\title{
Atala e Duque: igualdade e não discriminação sob a óptica interamericana
}

Bernardo de Souza Dantas Fico

\section{Resumo}

Este artigo analisa os avanços jurisprudenciais do Sistema Interamericano de Direitos Humanos na seara do direito à igualdade e à não discriminação, com foco nos dois casos decididos por sua Corte na matéria de direitos LGBTI. A garantia da igualdade, tanto formal quanto material, não é tarefa simples. Da análise de ambos os casos, pode-se inferir a tendência do Sistema Interamericano a colocar o casamento entre pessoas do mesmo gênero em patamar de igualdade completa (formal e material) em relação ao casamento entre pessoas de gêneros opostos. Ainda, depreende-se que a adoção de prática nacional que divirja do norte apontado pelo Sistema viola, dentre outros diplomas internacionais, o Pacto de San José da Costa Rica, podendo ensejar responsabilidade internacional ao Estado, ${ }^{\mathrm{I}}$ se processado. No contexto do Brasil, país que mais mata LGBTIs no mundo, esse debate é de grande relevo.

Palavras-chave: Igualdade - Não discriminação - Casamento - LGBTI Corte Interamericana.

I O artigo tratará de Estados genericamente considerados. 


\section{I. $\mathrm{O}$ direito à igualdade e à não discriminação em âmbito internacional: a inclusão da proteção a pessoas LG B T I}

O direito à igualdade e à não discriminação são basilares à proteção de direitos humanos em âmbito nacional e internacional. Relacionados, ambos os princípios possuem fortes ligações (GTIDH, 2003). Não nos alongaremos, neste artigo, a respeito de suas peculiares distinções (REYES-TORRES, 20I4), restringindo-nos a expor que, sob a óptica interamericana, o direito à igualdade se liga mais às obrigações do Estado de respeitar e garantir direitos (CTIDH, 20I6, §93) elencados pela Convenção Americana sobre Direitos Humanos (CADH ou Convenção de I969), enquanto a não discriminação enraíza-se mais especificamente na proteção da legislação interna (CTIDH, 20I6, \$93; OEA, I969, art. 24), que não pode ser desigual.

No Sistema Interamericano, esses direitos são garantidos pelos artigos I.I e 24 da Convenção. Esses artigos não mencionam explicitamente a proteção contra a discriminação por orientação sexual, mas deixam clara a possibilidade de interpretação evolutiva dos dispositivos para que alcancem, por exemplo, outras "naturezas ou condições sociais" (OEA, I969, art. I.I) não previstas quando da elaboração da Convenção. Versam os artigos I.I e 24 da Convenção Americana (OEA, I969):

Artigo I ${ }^{0}$ - Obrigação de respeitar os direitos

I. Os Estados-partes nesta Convenção comprometem-se a respeitar os direitos e liberdades nela reconhecidos e a garantir seu livre e pleno exercício a toda pessoa que esteja sujeita à sua jurisdição, sem discriminação alguma, por motivo de raça, cor, sexo, idioma, religião, opiniões políticas ou de qualquer outra natureza, origem nacional ou social, posição econômica, nascimento ou qualquer outra condição social.

[...]

Artigo 24 - Igualdade perante a lei

Todas as pessoas são iguais perante a lei. Por conseguinte, têm direito, sem discriminação alguma, à igual proteção da lei.

Isso se corrobora tanto por diplomas internacionais diversos, como o Pacto Internacional de Direitos Econômicos Sociais e Culturais (PIDESG) a partir do Comentário Geral I4 e os Princípios de Yogyakarta, quanto por decisões de Cortes Regionais de Direitos Humanos, como a Corte Europeia de Direitos Humanos ( $\mathrm{CtEDH})$ e a própria Corte Interamericana, a qual é categórica ao apontar que "já estabeleceu que a orientação sexual e a identidade de gênero 
das pessoas são categorias protegidas pela Convenção” (GTIDH, 20I6, §IO4, tradução nossa).

Os Comentários Gerais I4 e 20 ao Pacto Internacional de Direitos Econômicos Sociais e Culturais também explicitam que a menção a "sem discriminação alguma" em seu artigo 2.2 inclui "orientação sexual" (ECOSOG, 2000; 2009; GTIDH, 20I6, §IO9). Já os princípios de Yogyakarta são uma resposta a práticas sistemáticas de abuso contra a população LGBTI (YOGYAKARTA, 2007, Preâmbulo). O Princípio 2 de Yogyakarta determina que o direito à igualdade e à não discriminação inclui orientação sexual e identidade de gênero como categorias protegidas. O Princípio I3 expõe, dentre outros, que os direitos à seguridade social e à licença maternidade/paternidade devem ser garantidos sem discriminação. Dentre as obrigações estatais previstas sob esses princípios encontram-se: incluir a proteção à orientação sexual e à identidade de gênero na Constituição, ou em diploma adequado, por meio de emenda ou interpretação; e adotar leis que ajudem a eliminar a discriminação nos âmbitos público e privado.

Nesse mesmo sentido, a Corte Europeia se pronunciou em Oliari and others $v$. Italy determinando que "qualquer medida negando a casais de mesmo gênero benefícios existentes para casais de gêneros opostos casados [...] deve ser tratada presumidamente como uma forma de discriminação indireta em razão de orientação sexual." (GTEDH, 20I5, \$I42, tradução nossa). Segue esse mesmo entendimento a Corte Interamericana, quando explicita que a decisão sobre a guarda provisória das filhas da senhora Atala Riffo não podia levar em consideração sua orientação sexual, pois isso conferiria uma "diferença de tratamento baseada nessa categoria" (GTIDH, 20I2, \$98).

Cabe aos Estados absterem-se de criar, direta ou indiretamente, situações discriminatórias de jure ou de facto (CTIDH, 20I6, \$92). Por conseguinte, tanto leis discriminatórias quanto resultados discriminatórios de ações (ou omissões) do Estado implicam violação de sua responsabilidade internacional de promoção e garantia da igualdade e da não discriminação.

A Corte também indica, em casos recentes como Duque vs. Colómbia, que, acompanhando o desenvolvimento atual do direito internacional, deve-se conferir caráter diferenciado ao princípio fundamental da igualdade e não discriminação. Em acordo com a jurisprudência da Corte, esse princípio fundamental ingressou no domínio de jus cogens (CTIDH, 20I6, \$9I). Isso implica uma superioridade normativa desse direito, que passa a não poder ser derrogado por acordos entre Estados, ou preteridos em favor de um direito que esteja fora desse rol de normas cogentes. 
Nos últimos anos, uma das agendas temáticas que tem tomado forma no Sistema Interamericano de Direitos Humanos (SIDH, ou Sistema) é a dos direitos LGBTI. Atualmente com duas decisões proferidas pela Corte Interamericana de Direitos Humanos (CtIDH, ou Corte), Atala Riffoy niñas vs. Chile e Duque vs. Colómbia, e casos tramitando na Comissão Interamericana de Direitos Humanos (CIDH, ou Comissão), a questão do casamento igualitário e suas consequências se colocam como uma das vertentes de análise da Corte.

\section{Distinção e discriminação}

A Convenção Americana sobre Direitos Humanos não possui uma definição explícita de "discriminação", bem como não aponta um conceito para "distinção". O mesmo ocorre com o Pacto Internacional de Direitos Civis e Políticos (do inglês, ICGPR). Contudo, isso não impede que se extraia da normativa internacional, bem como da jurisprudência de Cortes Regionais de Direitos Humanos, o alcance dessas duas palavras.

Diplomas internacionais, como a Convenção Internacional sobre a Eliminação de todas as Formas de Discriminação Racial e a Convenção sobre Eliminação de todas as Formas de Discriminação contra a Mulher, trazem em seus primeiros artigos o significado de "discriminação". Nessa seara, também se posicionou o Comitê de Direitos Humanos da Organização das Nações Unidas (UNHRG, I989) em sua Observação Geral I8, ao recortar "discriminação" como:

[...] toda distinção, exclusão, restrição ou preferência que se baseiem em determinados motivos, como raça, cor, gênero, idioma, religião, opinião política ou de outra natureza, origem nacional ou social, propriedade, nascimento ou qualquer outra condição social e que tenham por objetivo ou por resultado anular o prejudicar o reconhecimento, gozo ou exercício, em iguais condições, dos direitos humanos e liberdades fundamentais de todas as pessoas.

Portanto, pode-se concluir que há discriminação quando se percebem dois fatores: a diferença de tratamento e a inexistência de motivação objetiva e razoável para tal (CTIDH, 20I6, §IO6; 20I4b, \$2I9). A análise de adequação deste segundo requisito pela Corte Interamericana joga luz sobre dois critérios: (i) perseguição de fím legítimo e (ii) relação razoável de proporcionalidade (CTIDH, 20I6, §IO6; 20I4a, \$200; 20I4b, \$2I9). Assim, se a diferença de tratamento não ocorre com a intenção de se proteger um fim legítimo, ou se 
o meio para alcançar essa proteção for desproporcional ou inócuo, então esse tratamento é discriminatório.

Por outro lado, se a diferença de tratamento se justificar, temos o que chamamos "distinção". A distinção é a face legal do tratamento diferenciado. Nela, apesar de haver uma resposta diferente da usual, esta se justifica por ser proporcional e necessária a um objetivo legítimo da sociedade. A tutela que se dá às crianças, por exemplo, é claramente diferente da que se provê a adultos capazes. Contudo, essa diferença se justifica pelo legítimo interesse de proteger as crianças e dar proporcionalidade às medidas.

A Corte aponta que não há uma vedação absoluta à diferença de tratamento, como ilustra o próprio caso da doutrina da maior proteção da criança. Todavia, quando da restrição de direitos, há a exigência de fundamentação rigorosa. A fundamentação é imperativa para que não se disfarce de distinção, o que materialmente se mostra discriminatório. Assim, as justificativas do Estado para tal restrição devem ser particularmente sérias e devem exaurir em argumentação todos os pontos que, diferenciando, possam ser discriminatórios (CTIDH 20I6, §IO6; 20I2, \$I24). Com isso em mente, passamos a analisar os casos de Karen Atala Riffo e Ángel Alberto Duque.

\section{O caso de Karen Atala Riffo e a guarda de menores}

Nos julgamentos de guarda, o fator decisório analisado deve ser a capacidade maternal ou paternal dos indivíduos em questão. Nesse sentido, incluir na análise a respeito da capacidade de prover um lar adequado a seus filhos condições alheias a esta habilidade é prejudicial aos pais e às próprias crianças. Quando essa mistura se dá com o intuito ou efeito de estigmatizar ou inferiorizar um grupo social, pr'além de prejudicar a vida familiar torna-se uma violação ao direito à igualdade e à não discriminação.

Karen Atala Riffo casou-se em 1993 com Ricardo Jaime López Allende. Em I994, I998 e I999 nasceram respectivamente M., V., e R. Em 2002, a sra. Atala e o sr. Allende resolveram terminar o casamento, separando-se de fato. Manteve a guarda das filhas a senhora Atala que, meses depois, passou a conviver com sua nova companheira, Emma de Ramón. No início do ano seguinte, o sr. Allende iniciou processo para tomar a guarda das filhas, pois acreditava que o desenvolvimento das meninas encontrava-se em grave risco. Justificou então sua preocupação com o fato de que sua ex-mulher passara a viver em uma relação não heterossexual. Corridos todos os recursos disponí- 
veis, a guarda foi concedida ao pai pela Corte Suprema de Justiça do Chile em 3I de maio de 2004 (CTIDH, 20I2, \$\$30-58).

Em 24 de fevereiro de 20I2, a Corte Interamericana pronunciou-se a respeito do caso. A Corte aplicou o controle de convencionalidade e analisou a adequação das decisões judiciais internas chilenas em relação à Convenção Americana, concluindo por sua violação. Apesar da fundamentação da Corte Suprema de Justiça ter se dado em relação à proteção das crianças M., V., e R., os estereótipos utilizados demonstram tratamento discriminatório em relação a Karen Atala Riffo (CTIDH, 20I2, \$\$66, 285-299).

Esse tipo de tratamento, a Corte aponta, atenta contra os artigos I.I e 24 da Convenção Americana sobre Direitos Humanos. Ainda que não houvesse determinação legislativa proibindo a sra. Atala de preservar a guarda das filhas, a decisão que concedeu a tutela ao pai não trata de suas capacidades maternais, mas de sua orientação sexual como subsídio para dirimir a questão (CTIDH, 20I2, \$276).

Ao analisar o caso utilizando-se da ferramenta desenvolvida pelas Cortes Regionais de Direitos Humanos, o teste de três partes na limitação de direitos, percebe-se a desproporção da decisão chilena. Apesar do "interesse superior da criança" (CTIDH, 2002, \$\$56-6I) ser de fato um fim legítimo a ser perseguido, aponta a Corte que mencioná-lo não torna a decisão pertinente ou proporcional. Para que esse princípio precise ser aplicado, deve-se in concreto provar a existência de algum risco às crianças em questão.

No caso em tela, não se apresentou qualquer ameaça real às filhas da sra. Atala, apenas alegações estereotipadas em relação à orientação sexual da mãe. Ainda, não deve o interesse superior da criança ser utilizado como forma de mascarar e permitir que ações discriminatórias ocorram. Assim, ainda que a decisão acerca da guarda se funde em legislação existente e adequada, e persiga o legítimo objetivo de garantir maior proteção às crianças, não observa a desproporção e a ausência de correlação da medida tomada com o resultado perseguido (GTIDH, 2OI2, \$§IO7-II4).

A retirada da guarda ocorre fundamentalmente em decorrência da orientação sexual da mãe das meninas. Dessa forma, a decisão do tribunal interno constitui-se em um ato que prejudica os direitos da sra. Atala e de suas filhas, baseando-se na orientação sexual da mãe. Apesar da legítima preocupação de possível discriminação social que possam as filhas da sra. Atala sofrer, não cabe ao Estado se utilizar desse argumento como razão para gerar ainda mais discriminação e perpetuar um cenário de propagação de preconceito.

É dever do Estado agir para eliminar a discriminação de seu território, não produzir decisões artificiais para inutilmente tentar blindar as três 
meninas em questão. Mudanças nas dinâmicas familiares ocorrem. Estas podem, e devem, ser absorvidas pela sociedade. Divorciados, mães ou pais solteiros, dentre outros, um dia ensejaram argumentos falaciosos similares aos traçados hoje em relação a casais de mesmo gênero. Ainda, adota-se o entendimento da Corte Europeia em Christine Goodwin vs. the United Kingdom de que "considerando-se o direito ao casamento, não se deve entender gênero como determinado puramente por critérios biológicos" (GTEDH, 2OIO, §52; 2002, §IOO, tradução nossa), sendo o termo portanto mais apropriado que sexo, o qual denota características biologizantes e de estigma à população trans.

\section{O caso de Alberto Duque e o direito à pensão por morte}

A pensão de sobrevivência é direito garantido em diversos sistemas legais para proteger a família do trabalhador dos efeitos econômicos que sua morte possa causar. Em decisões acerca do benefício previdenciário por falecimento, deve-se analisar se a pessoa falecida cumpria com todos os requisitos para a concessão do montante a quem dele tem direito. Dentre os possíveis beneficiários está o cônjuge da pessoa falecida. Assim, a recusa em conceder a pensão por se tratar de um casal não heterossexual é uma violação dos direitos à igualdade e à não discriminação, protegidos pelos Artigos I. I e 24 da Convenção Americana.

Ángel Alberto Duque e o sr.J.O.J.G. viveram como casal até I5 de setembro de 200I, data em que J.O.J.G. veio a falecer. Duque então solicitou à Companhia Colombiana Administradora de Fundos de Pensões e Separação (Colfondos), em I9 de março de 2002, os requisitos para obter a pensão de sobrevivência de seu companheiro, J.O.J.G. Em resposta, foi informado de que era inelegível como beneficiário, tendo a Colfondos alegado que "a legislação colombiana em matéria de seguridade social [...] contempla que são beneficiários [...] cônjuge, companheira e companheiro sobreviventes”, contudo, destaca que "esta qualidade de beneficiário, a lei a estabelece da união de um homem e uma mulher; atualmente tal legislação não contempla a união de duas pessoas do mesmo sexo" (GTIDH, 20I6, \$\$68-70, tradução nossa).

Somente no ano de 2007 a Corte Constitucional da Colômbia reconheceu jurisprudencialmente a constituição de casais do mesmo gênero. Dessa forma, casais que cumpram com os requisitos legais passam a constituir união conjugal, independentemente de serem constituídos por um 
homem e uma mulher, dois homens, ou duas mulheres. Decorre disso que os benefícios antes reservados a casais heterossexuais, pela ausência de reconhecimento da união conjugal homossexual, passam a ser garantidos a todos, incluindo a pensão por sobrevivência (CTIDH, 20I6, §8I). Destaca a Corte que não há justificativa que autorize tratamento diferenciado ao sr. Duque pelo simples fato de este constituir um casal homossexual (CTIDH, 20I6, \$I2I).

Indicou o Estado no caso que, a partir de 20I0, Alberto Duque encontrava-se em igualdade de condições em relação a cônjuges sobreviventes de casais heterossexuais (CTIDH, 20I6, \$I32). Isso, no entanto, não desconfigura a discriminação sofrida pelo sr. Duque desde o falecimento de seu companheiro, em setembro de 200I. Determina portanto a Corte que houve tratamento discriminatório de Ángel Alberto Duque desde a morte de J.O.J.G. até o ano de 20IO. Todavia, apesar da equiparação a casais heterossexuais ter sido realizada, desejava o Colfondos aplicar a regra do artigo 488 do Código Substantivo do Trabalho.

Esse artigo determina que os direitos regulados pelo referido código, quando não pleiteados no prazo de 3 anos, prescrevem. Dessa forma, desejava-se evitar o pagamento de quase uma década de pensões que haviam sido negadas ao sr. Duque por motivação discriminatória. Com a negativa em pagar os valores devidos sob a alegação de prescrição, decide a Corte que o Estado colombiano persistia na violação dos direitos de Alberto Duque. Isso porque os valores não foram pagos como consequência da discriminação sofrida por casais homossexuais. Por conseguinte, os pagamentos retroativos ainda não realizados constituíam ingerência ao direito à igualdade e não discriminação do peticionário (GTIDH, 20I6, \$I37).

Cabe ao ente estatal a proteção primária aos direitos humanos em seu território. O Estado colombiano viola esse dever ao impedir que o viúvo de J.O.J.G, ainda que cumprindo os requisitos de elegibilidade, receba a pensão deixada por seu cônjuge, sob alegação de proteção à família. Não se demonstra, contudo, o vínculo entre proteger a família e impedir o acesso de casais homossexuais à pensão de sobrevivência.

\section{v. Conclusão}

Entendemos que cabe aos Estados regular internamente sua legislação e a aplicação desta, de forma a não causar situações de discriminação de direito ou de fato (CTIDH, 20I6, \$85; 20I2, \$80). Ao Poder Judiciário compete fazer 
controle difuso de convencionalidade ex officio, com o intuito de garantir a compatibilidade de suas decisões com a jurisprudência da Corte (CTIDH, $2012, \$ 282$; 20I6, \$85). Nesse sentido, não se disputa a ilicitude e contrariedade à $\mathrm{CADH}$ de tratamentos diferenciados com base na orientação sexual de qualquer indivíduo (CTIDH, 20I6, \$IO5; 20I2, \$235).

Na seara matrimonial, isso deve incluir não somente os demonstrados direitos de manutenção da guarda de descendentes quando da separação do casal e recebimento de pensão por sobrevivência, mas estender-se a toda e qualquer garantia conferida a casais heterossexuais. Negar a proteção de um direito com base na orientação sexual do indivíduo equivale a deslegitimar uma alternativa válida de vida e sancionar tais pessoas por isso. Inexistem razões objetivas para tratar de maneira diferente pessoas que, por sua orientação sexual, decidem compor um casal com alguém de mesmo gênero (CTIDH, 20I6, \$§I2O-I2I; 2OI2, \$\$I33-I40).

Cumpre salientar que a "falta de consenso interno de alguns países em relação ao respeito pleno dos direitos das minorias sexuais não pode ser considerado argumento válido para negar-lhes ou restringir-lhes seus direitos humanos" (CTIDH, 20I6, \$I23, tradução nossa). Adotar tal postura negacionista de direitos implicaria a continuidade da discriminação histórica e estrutural sofrida por essas minorias (CTIDH, 20I6, \$I23). Para se decidir questões nessa matéria, deve o tribunal olhar somente para as obrigações internacionais de igualdade e não discriminação contraídas pelo Estado, não para a possível controvérsia ou resistência de determinados setores do país (CTIDH, 2OI2, \$92).

Portanto, a despeito da possibilidade de resistência populacional majoritária à consecução dos direitos de minorias sexuais, é dever do Estado implementá-los. Como já decidiu a Corte Interamericana em casos anteriores, a mera aprovação ou recusa popular acerca de um direito não faz com que essa seja a opção mais protetiva e adequada (CTIDH, 20II, \$\$238-239). O escopo de decisões populares não deve incluir direitos de grupos minoritários, sob pena de se criar um mecanismo de negação de direitos humanos, os quais são essencialmente contramajoritários (RAMOS, 20I3).

Ao andar na contramão do Sistema Interamericano, essa questão demonstra não somente posicionamento retrógrado e estereotipado em relação ao conceito de família (GTIDH, 20I2, \$§I4I-I46; 20I6, §§I59-I6I), mas também o desconhecimento das obrigações internacionais assumidas pelo Estado. Interpretadas pela Corte, essas obrigações indicam claramente o dever do Estado de promover a equalização entre relações conjugais hétero e homossexuais, tanto de jure quanto de facto. 


\section{Referências}

COMITÊ DE DIREITOS HUMANOS DA ORGANIZAÇÃO DAS NAÇÕES UNIDAS (UNHRG). Observação Geral, n. I8, HRI/GEN/I/Rev.9 (Vol. I), IO nov. I989.

CORTE EUROPEIA DE DIREITOS HUMANOS (CtEDH). Case of Christine Goodwin vs the United Kingdom, Merits, II jul., Application n. 28957/95, 2002.

Case of Schalk and Kopf vs Austria, Merits, 24 jun., Application n. 3014I/O4, 2010.

. Case of Oliari and others v. Italy, Merits, 2I jul., Application n. I8766/II and 36030/II, 2015 .

CORTE INTERAMERICANA DE DIREITOS HUMANOS (CtIDH). Condición Jurídica y Derechos Humanos del Niño. Opinión Consultiva, s. A, n. I7, 28 ago. 2002.

Condición Jurídica y Derechos de los Migrantes Indocumentados. Opinión Consultiva, s. A, n. I8, I7 sep. 2003.

Caso Gelman vs. Uruguay. Fondo y Reparaciones, s. C, n. 22I, 24 feb. 20 II.

. Caso Atala Riffoy niñas vs. Chile. Fondo, Reparaciones y Costas, s. G, n. 239, 24 feb. 2012.

Caso Norín Catrimán y otros (Dirigentes, Miembrosy Activistas del Pueblo Indígena Mapuche) vs. Chile. Fondo, Reparaciones y Costas, s. C, n. 279, 29 may. 20I4a.

Caso Espinoza Gonzáles Vs. Perú. Excepciones Preliminares, Fondo, Reparaciones y Costas, s. C, n. 289, 20 nov. 20I4b.

- Caso Duque vs. Colómbia. Excepciones Preliminares, Mérito, Reparação e Custas, s. C, n. 310, 26 feb. 2016.

UNITED NATIONS EGONOMIG AND SOGIAL GOUNGIL (Ecosoc). The Right to the Highest Attainable Standard of Health (Art. I2 of the International Covenant on Economic, Social and Cultural Rights), General Comment, n. I4, E/C.I2/2000/4, II aug. 2000.

. Non-discrimination in economic, social and cultural rights (Art. 2, para. 2, of the International Covenant on Economic, Social and Cultural Rights), General Comment, n. 20, E/C.I2/GC/20, 02 jul. 2009.

ORGANIZAÇÃO DOS ESTADOS AMERICANOS (OEA). Convenção Americana sobre Direitos Humanos. San José: OEA, I969.

RAMOS, A. G. Teoria Geral dos Direitos Humanos na Ordem Internacional. 3. ed. São Paulo: Saraiva, 20I3.

REYES-TORRES, Amaury A. El principio de igualdad y no discriminación como límite al margen de apreciación en el reconocimiento del matrimonio entre 
personas del mismo sexo. American University International Law Review, Washington, v. 29, 2014 .

YOGYAKARTA. Yogyakarta Principles on the Application of International Human Rights Law in Relation to Sexual Orientation and Gender Identity. Yogyakarta: [s.n.], 26 mar. 2007.

\section{wer}

Bernardo de Souza Dantas Fico é granduando em Direito pela Universidade de São Paulo. bsd.fico@gmail.com 